\title{
ROLE OF TOPICAL PHENYTOIN IN DIABETIC FOOT ULCER CARE - A RANDOMISED CONTROL TRIAL
}

\author{
R. Soundarapandiyan ${ }^{1}$, R. Srikanth'2, V. Udhayasankar ${ }^{3}$
}

1 Professor, Department of General Surgery, Government Vellore Medical College, Vellore.

${ }_{2}^{2}$ Assistant Professor, Department of General Surgery, Government Vellore Medical College, Vellore.

3Junior Resident, Department of General Surgery, Government Vellore Medical College, Vellore.

\section{ABSTRACT}

\section{BACKGROUND}

India is becoming the world capital of diabetes mellitus. Diabetes mellitus has many number of complications. Patients with diabetes mellitus seek medical attention for their foot problems more often. Among those who developed diabetic foot problems, $15 \%$ underwent some type of toe to foot amputations.

Aim of this study is to assess the efficiency of topical phenytoin on diabetic foot ulcers, Meggitt's grade 1 and 2.

\section{MATERIALS AND METHODS}

A total of 100 non-insulin-dependent diabetes mellitus patients with grade 1 and grade 2 Meggitt's clinical classification who got admitted were included in this study in Department of General Surgery, Government Vellore Medical College Hospital. 100 patients were randomised into two groups 50 each. Patients subjected to topical phenytoin dressing were classified as study group and those who underwent normal saline wound dressings were classified as control group. The study aimed at assessing the rate of granulation tissue formation, ulcer surface area reduction, and duration of stay in the hospital.

\section{RESULTS}

After 14 days, the wound healing was assessed in terms of granulation tissue and reduction in ulcer area. In study group, the presence of healthy granulation tissue noted was $70 \%$, and it was about $30 \%$ in control group. Wound i.e. ulcer area reduction was $78 \%$ in study group, only $38 \%$ in control group. The mean duration of stay in hospital also was reduced in phenytoin group.

\section{CONCLUSION}

This study concludes that topical phenytoin sodium promotes early wound healing and also review of literature reveals the same.

\section{KEYWORDS}

Diabetic Foot Ulcer, Granulation Tissue, Topical Phenytoin, Conventional Dressings.

HOW TO CITE THIS ARTICLE: Soundarapandiyan R, Srikanth R, Udhayasankar V. Role of topical phenytoin in diabetic foot ulcer care - A randomised control trial. J. Evolution Med. Dent. Sci. 2017;6(4):265-268, DOI: 10.14260/Jemds/2017/60

\section{BACKGROUND}

India is becoming the world capital of diabetes mellitus.(1) Diabetes Mellitus is a modern world disease. Major reason for hospitalisation in diabetic patients are due to diabetic foot complications.(2) Diabetes mellitus patients have up to $25 \%$ risk of developing diabetic foot ulcer.(3) Among those with foot complications, $15 \%$ will undergo various types of foot amputations.(4) Management of diabetic foot mainly depends on its grade, vascularity and presence of infection.(5) In Indians with lack of knowledge regarding foot complications of Diabetes Mellitus, Habits like bare foot walking, hot climate, poor hygiene, etc. increases the chance of diabetic foot complications.(6)

Phenytoin (Diphenylhydantoin) was introduced in therapy in 1937 for effective control of convulsive disorders with a common side effect being gingival hyperplasia.(7) Phenytoin stimulates the connective tissue, which helps in wound healing. The beneficial effect of phenytoin has been shown in promoting healing of decubitus ulcers, venous

Financial or Other, Competing Interest: None.

Submission 21-12-2016, Peer Review 03-01-2017,

Acceptance 05-01-2017, Published 12-01-2017.

Corresponding Author:

Dr. R. Soundarapandiyan,

Professor, Government Vellore Medical

College Hospital, Vellore-632011, Tamilnadu.

E-mail: drrsoundar7@gmail.com

DOI: $10.14260 /$ jemds $/ 2017 / 60$ stasis ulcers, traumatic wounds, burns, leprosy trophic ulcers.(8)

\section{MATERIALS AND METHODS}

This study was conducted in Government Vellore Medical College Hospital, Vellore, Tamilnadu. 100 patients were included in this study randomised in to two groups 50 each, all of them belong to Meggitt-Wagner diabetic foot ulcer grade 1 and grade 2 .

\section{Inclusion Criteria}

- Patients with chronic ulcers with diabetes mellitus.

- Wound size $<5 \%$ TBSA.

\section{Exclusion Criteria}

- Grade 3, 4, 5 foot ulcers according to Meggitt-Wagner clinical classification.

- Chronic ulcer of other aetiology.

- Other comorbid conditions like renal failure, generalised debility which adversely affect wound healing.

- Patients with allergy to phenytoin.

Diabetic Foot Ulcer Wagner Classification

Grade 0- No risk

Grade 1 - Superficial ulcers.

Grade 2 - Deep ulcers.

Grade 3 - Deep ulcers with abscess.

Grade 4 - Gangrene - Limited.

Grade 5 - Gangrene - Extensive. 


\section{Ethical Concerns}

The study proposal was approved by the Ethical Committee of our college. All the patients were informed about this study and written informed consent was obtained.

\section{Sample Selection and Grouping}

The included population was divided in to two groups, 50 each for control and study group randomly by lottery method. A total of 50 patients inducted as a study group for the use of topical phenytoin powder, and the rest 50 were followed with a classical wound dressing with p-iodine and saline wash with magnesium sulfate dressing taken as a control group.

\section{Procedure}

A single $100 \mathrm{mg}$ phenytoin sodium capsule was opened and placed in $5 \mathrm{~mL}$ of sterile normal saline to form a suspension. The drug is applied as suspension over the wound with sterile gauze at $20 \mathrm{mg} / \mathrm{cm}^{2}$ TBSA. Conventional dressing was done with $5 \% \mathrm{w} / \mathrm{v}$ povidone-iodine solution. Before applying the dressing, the wound was cleaned with normal saline.

Before applying the phenytoin in study group as well as in control group, the wound was thoroughly debrided and tissue paper mapping was done. Tissue paper mapping was repeated after 14 days in both groups. Both the groups underwent wound dressings twice a day. Patients in both the groups followed up to 14 days.

At the end of 14 days, the following parameters were compared in both the groups.

1. Rate of granulation tissue formation.

2. Reduction in wound surface area.

3. Duration of hospital stay.

\section{RESULTS}

A demographic study of patients inducted into our study shows age ranges from 30 to 80 . 51-70 years age group patients are in majority in this study. Mean age in study group was $54.6 \pm 6.1$, in control group was 53.1 \pm 6.83 . Males constitute $65 \%$ of the inducted patients and females $35 \%$. Age and sex distribution was same in each group, so demographic variations were not influenced in this study. The sites of the presence of an ulcer in each group were also studied. The findings are tabulated in Table 1 and Figure 1.

\begin{tabular}{|c|c|c|c|}
\hline Variables & $\begin{array}{c}\text { Study Group } \\
\mathbf{n = 5 0}\end{array}$ & $\begin{array}{c}\text { Control Group } \\
\mathbf{n = 5 0}\end{array}$ & Significant \\
\hline Male & 33 & 32 & $\mathrm{P}=0.578$ \\
\hline Female & 17 & 18 & \\
\hline Mean Age & $54.63 \pm 6.1$ & $53.1 \pm 6.83$ & $\mathrm{P}=0.413$ \\
\hline Ulcer in Dorsum & 26 & 24 & \\
\hline Ulcer in Heel & 18 & 17 & \\
\hline Other Sites & 6 & 9 & \\
\hline \multicolumn{4}{|c|}{ Table 1. Demographic Profile of Patients } \\
in both Study and Control Group \\
\hline
\end{tabular}

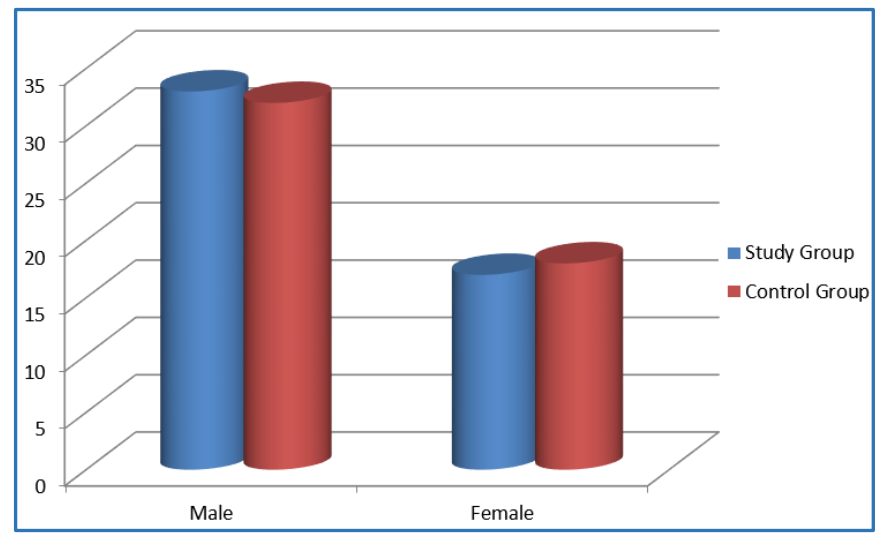

Figure 1. Shows Age and Sex wise Distribution of Cases

The surface area of the ulcer predominantly corresponds in each group, and the majority of ulcers were of $9-15 \mathrm{~cm}$ size and no significant variations noted among the group. Wound size reduction was assessed.

After 14 days, the healthy granulation tissue formed in $70 \%$ of study group and in only $30 \%$ in control group which is shown in Table 2 and Figure 2. The difference is also statistically significant $(\mathrm{P}<0.005)$.

\begin{tabular}{|c|c|c|c|c|c|c|}
\hline Day & Group & A & B & C & D & E \\
\hline \multirow{2}{*}{7} & Study Group & 0 & 2 & 18 & 30 & 0 \\
\cline { 2 - 7 } & Control Group & 1 & 6 & 33 & 10 & 0 \\
\hline \multirow{2}{*}{14} & Study Group & 0 & 0 & 15 & 33 & 2 \\
\cline { 2 - 7 } & Control Group & 1 & 6 & 28 & 15 & 0 \\
\hline
\end{tabular}

Table 2. Effect of Topical Phenytoin and Control Treatment on Clinical Improvement of Patients

A - Deterioration

B - Status Quo

C - Unhealthy Granulation Tissue

D - Healthy Granulation Tissue

E - Complete Healing

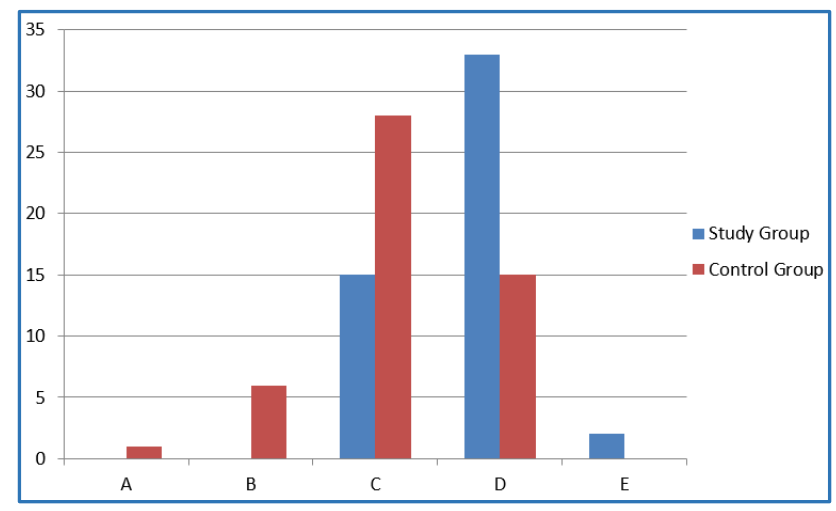

Figure 2. Effect of Topical Phenytoin and Control Treatment on Clinical Improvement of Patients on Day 14

At the end of 14 days, wound reduction was $78 \%$ in the study group, and 38\% in control group - shown in table 3 and figure 3. This difference is also statistically significant $(\mathrm{P}=0.045)$. 


\begin{tabular}{|c|c|c|}
\hline \multirow{2}{*}{ Day } & \multicolumn{2}{|c|}{ Wound Reduction } \\
\cline { 2 - 3 } & Study Group & Control Group \\
\hline 7 & $65 \%$ & $26 \%$ \\
\hline 14 & $78 \%$ & $38 \%$ \\
\hline \multicolumn{3}{|c|}{ Table 3. Effect of Reduction in Wound Surface Area } \\
in Topical Phenytoin versus Control Group of Patients \\
\hline
\end{tabular}

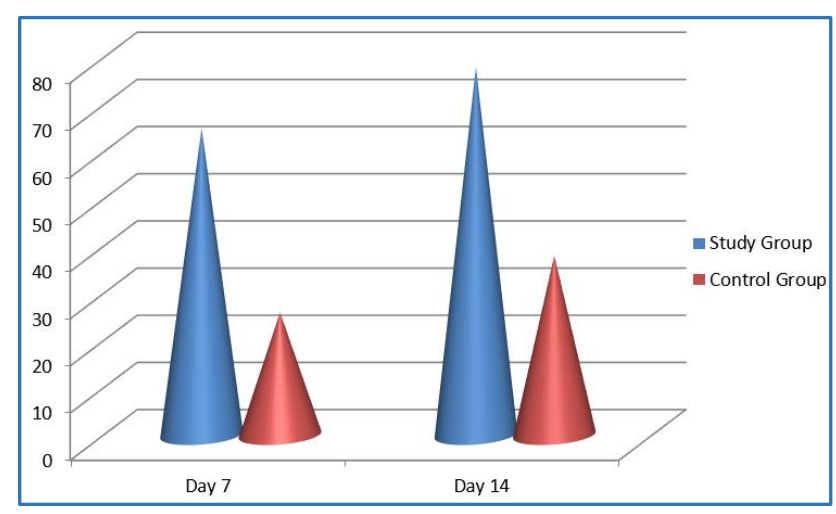

Figure 3. Effect of Reduction in Wound Surface Area in Topical Phenytoin versus Control Group of Patients

The duration of hospital stay was prolonged in patients in the control group. The mean duration of stay for patients with diabetic foot using phenytoin topical application was 19 days, for the control group it was 25 days. This also shows the economic burden on the family.

\section{DISCUSSION}

Phenytoin has been investigated as a treatment for more than 100 diseases. Numerous allergies, proliferative, idiosyncratic cutaneous side effects have been reported with its use.(9) A frequent observed and unwanted side effect of phenytoin, an anticonvulsant medication, is gingival hyperplasia, especially in children. This side effect suggested that phenytoin can induce the growth of connective tissue, and may have the ability to promote wound healing.

In 1939 Kimball and Horan first observed that gingival hyperplasia occurred in some patients treated with phenytoin. This stimulated the first controlled clinical trial in 1958, which found that the periodontal patients with surgical wounds who were pre-treated with oral phenytoin had less inflammation, less pain, and accelerated healing when compared with controls.(10)

Phenytoin promotes wound healing by following mechanisms: Stimulation of fibroblast proliferation, enhancing the formation of granulation tissue, decreasing collagenase activity, inhibition of glucocorticoid activity, direct or indirect antibacterial activity by affecting inflammatory cells, neovascularisation and phenytoin increases gene expression of the platelet derived growth factor $\beta$ chain in macrophage and monocytes. It is not known if phenytoin has intrinsic antibacterial activity or whether the effect of phenytoin on the bacterial load of wounds is mediated indirectly by effects on inflammatory cells and neovascularisation.(11-14)

The prospective, controlled trial by Muthukumarswamy et al(11) examined the use of topical phenytoin versus control therapy in 100 non-insulin-dependent diabetic patients with foot ulcers. In the control group $(n=50)$, a sterile occlusive dressing was applied daily. In the phenytoin group $(n=50)$, phenytoin powder was applied in a "thin layer" to the ulcer surface, and then dry dressing applied daily. Mean healing time was 21 days in the phenytoin group compared to 45 days in the control group $(\mathrm{p}<0.05 \%)$.

Modéer and Andersson in 1990,(15) in their study, on regulation of epidermal growth factor receptor metabolism in gingival fibroblasts proved that phenytoin significantly increases epidermal growth factor receptors in the fibroblast resulting in the gingival hyperplasia.

DaCosta et al in 1998,(16) by their experimental study proved phenytoin enhances the fibroblast infiltration with neovascularisation and significantly increases the tensile strength of healed wounds.

Tauro LF et al(8) observed 200 patients with diabetic ulcers. Hundred patients underwent topical phenytoin dressing while remaining underwent conventional wound care. The results were compared after 14 days. In study group, mean rate of granulation tissue formation was 87.94\%, mean graft take-up was $92.31 \%$ and mean hospital stay was 32.26 days with negative culture sensitivity $70 \%$. The control group showed the mean rate of granulation tissue formation was $74.64 \%$, the mean graft take-up was $86.15 \%$ of total ulcer surface area and mean hospital stay was 54 days with negative culture sensitivity $54 \%$. They concluded that topical phenytoin aids in faster healing of diabetic wounds with better graft take up and decreased hospital stay. A study conducted by Pai et al also showed good granulation tissue with topical phenytoin.

Anstead et al(12) reported that phenytoin has promoted healing in a massively necrotised Grade 4 decubitus ulcer not responding to any other therapy.

Pendse et al(4) have proved in their study $50 \%$ wounds treated with phenytoin had negative bacterial culture on 7 th day of treatment, whereas in the control group only $17 \%$ had negative culture.

Shaw et al(17) did a systematic review of role of phenytoin as topical agent in the healing of diabetic ulcers using PubMed, Medline, and Cochrane database with 14 available randomised controlled trials and concluded that use of phenytoin has moderate evidence to confirm and support as topical therapeutic agents in not only diabetic ulcers but also varicose leg ulcers and necrotic wounds.

\section{CONCLUSION}

This prospective randomised control study shows enhanced wound healing and sense of well-being in individuals with diabetic foot ulcer treated with topical application of phenytoin than the other classical wound dressing materials. But further studies with larger sample are needed in the future before topical phenytoin dressing can be added to the wide spectrum of treatment modalities available in the management of diabetic ulcers.

\section{REFERENCES}

[1] Kaveeshwar SA, Cornwall J. The current state of diabetes mellitus in India. AMJ 2014;7(1):45-8.

[2] Ahmed AM. History of diabetes mellitus. Saudi Med J 2002;23(4):373-8.

[3] Singh N, Armstrong DG, Lipsky BA. Preventing foot ulcers in patients with diabetes. JAMA 2005;293(2):217-28. 
[4] Pendsey SP. Understanding diabetic foot. Int J Diabetes Dev Ctries 2010;30(2):75-9.

[5] Frykberg RG, Armstrong DG, Giurini J, et al. Diabetic foot disorders: a clinical practice guideline. American college of foot and ankle surgeons. J Foot Ankle Surg 2000;39(5 Suppl):S1-60.

[6] Viswanathan V, Shobhana R, Snehalatha C, et al. Need for education on footcare in diabetic patients in India. J Assoc Physicians India 1999;47(11):1083-5.

[7] Pereira CA, Ade AO. Assessment of the effect of phenytoin on cutaneous healing from excision of melanocytic nevi on the face and on the back. BMC Dermatol 2010;10:7.

[8] Tauro LF, Shetty P, Dsouza NT, et al. A comparative study of efficacy of topical phenytoin vs conventional wound care in diabetic ulcers. International Journal of Molecular Medical Science 2013;3(8).

[9] Meritt HH, Putnam TJ. Sodium diphenylhydantoinate in the treatment of convulsive disorders. JAMA 1938;111(12):1068-73.

[10] Shapiro M. Acceleration of gingival wound healing in non-epileptic patients receiving diphenylhydantoin sodium (Dilantin, Epanutin). Exp Med Surg 1958;16(1):41-53.
[11] Muthukumarasamy MG, Sivakumar G, Manoharan G. Topical phenytoin in diabetic foot ulcers. Diabetes Care 1991;14(10):909-11.

[12] Anstead GM, Hart LM, Sunahara JF, et al. Phenytoin in wound healing. Ann Pharmacother 1996;30(7-8):76875.

[13] Talas G, Brown RA, McGrouther DA. Role of phenytoin in wound healing-a wound pharmacology perspective. Biochem Pharmacol 1999;57(10):1085-94.

[14] Genever PG, Cunliffe WJ, Wood EJ. Influence of the extracellular matrix on fibroblast responsiveness to phenytoin using in vitro wound healing models. $\mathrm{Br} \mathrm{J}$ of Dermatol 1995;133(2):231-5.

[15] Modéer T, Andersson G. Regulation of epidermal growth factor receptor metabolism in gingival fibroblasts by phenytoin in vitro. J Oral Pathol Med 1990;19(4):188-91.

[16] DaCosta ML, Regan MC, al Sader M, et al. Diphenylhydantoin sodium promotes early and marked angiogenesis and results in increased collagen deposition and tensile strength in healing wounds. Surgery 1998;123(3):287-93.

[17] Shaw J, Hughes CM, Lagan KM, et al. The clinical effect of topical phenytoin on wound healing: a systematic review. Br J Dermatol 2007;157(5):997-1004. 